\title{
ATLAS BREVE DE LA VIDA Y ASOCIACIONES EMPÁTICAS, HACIA EL PAISAJE-ESCUELA
}

Carla Urbina 


\section{CARLA URBINA}

Doctora (Cand.) en Urbanismo en la Universidad Federal de Rio de Janeiro (Brasil). Master en Paisajismo y Especialista en Recuperación de Paisajes y Jardines históricos, Universidad Politécnica de Madrid (España). Magister en Diseño Urbano, Universidad Metropolitana (Venezuela). Arquitecta, Universidad Rafael Urdaneta (Venezuela). Premio Nacional de Arquitectura de Venezuela, 2017.

FECHA DE RECEPCIÓN: 13 de junio de 2018

FECHA DE ACEPTACIÓN: 3 de agosto de 2018.

REGISTRO BIBLIOGRÁFICO: URBINA, C. (2017) Atlas breve de la vida y asociaciones empáticas, hacia el paisaje - escuela. Anales de Investigación en Arquitectura, 7, 67-84.

Avance de revisión teórico-práctica de la Tesis del Doctorado en Urbanismo de PRORB-UFRJ/ Brasil (2017-2021): El paisaje como experiencia de transformación cultural. Paisaje escuela y campus universitario. Autora: Carla Urbina. Orientadora: Lúcia Maria Sá A. Costa. 


\section{RESUMEN}

“Atlas breve de la vida, hacia el paisaje-escuela" una raicilla, que dejará emerger los autores guía para la revisión teórico-práctica de la investigación: “El paisaje como experiencia de transformación cultural. Paisaje escuela y campus universitario”. Se basa en: Atlas Mnemosine (Warburg), Rizomas (Delleuze \& Guattari), Tiempo (Hawking) y en Nebulosas (Berenstein y Da Silva). Pretende mostrar al hommo sapiens como especie, parte integral e indivisible del paisaje, con aportes culturales (positivos o negativos). Como seres con conciencia podemos afirmar que "Somos paisaje", y por tanto buscamos explorar y colectar medios para minimizar la degradación del paisaje, que sería nuestra propia degradación.

Ese habitar de Heidegger, en el que estamos incluidos, podría también referirse a las relaciones de afecto con ese espacio construido, habitado, en la "topofilia” de Gastón Bachelard. La topofilia como espacio vivido, imaginado, defendido, amado. Porque ser te hace cuidar, al preservar o regenerar el paisaje se está cuidando el propio ser. El habitar de Heidegger, el proteger de Burle Marx y Stoneman Douglas, el accionar de Beauvior, el vivir de Thoureau, el aprender por la experiencia de Dewey y desde el placer de Epicuro; son experiencias que se asocian en el "Atlas breve de la vida". En él encontramos paralelismos en descubrimientos, estudios, transversalidades de ideas, en fin, nuestra vida es todo un enmarañado de raíces que se entrecruzan y comunican entre sí, como lo hacen los árboles.

Palabras clave: Atlas, vida, paisaje, educación, ciencia, arte, paisaje-escuela.

\section{ABSTRACT}

Brief Atlas of life, towards the Landscape of learning, is a rootlet that will show authors for the theoreticalpractical review of the Thesis: Landscape as an experience of cultural transformation. Landscape of learning and University Campus.

It is based on: Atlas Mnemosine (Warburg), Rhizome (Delleuze\&Guattari), Time (Hawking) and Nebulas (Berenstein \& Da Silva). It shows the Hommo sapiens as a specie, part of landscape, with its cultural contributions (positives and negatives). Conscious that "We are landscape", we are exploring and collecting ways to minimize the landscape degradation, that is our own degradation.

The idea of Live from Heiddeger, "to protect" from Roberto Burle Marx and Stoneman Douglas, "to act" of Beauvior, "to life" of Thoureau, "to learn by experience" of Dewey and by "the pleasure" of Epicuro; are experiences associated in the Brief Atlas of Life. On it we will found parallelism about discovering, studies, ideas; linked and communicating between each other as the roots of trees do.

Key words: Atlas, Life, Landscape, Education, Science, Art, Landscape of Learning. 


\section{ATLAS BREVE DE LA VIDA, HACIA EL PAISAJE-ESCUELA ${ }^{1}$}

El presente texto: "Atlas breve de la vida, hacia el paisaje-escuela" forma parte de una revisión teórico-práctica, una raicilla, que dejará emerger los autores guía para la revisión metodológica de la investigación: El paisaje como experiencia de transformación cultural. Paisaje escuela y campus universitario.

La premisa de la investigación es que la intervención en el paisaje como lugar educativo, puede fomentar el desarrollo de experiencias emocionales cotidianas, que ayudan a fomentar el conocimiento, valoración y compromiso para la preservación del paisaje, bajo el concepto de que se preserva (o en términos de Heidegger se cuida) lo que se quiere y se quiere lo que se conoce.

\section{SOMOS PAISAJE}

Martin Heidegger cree que "no existen los hombres y además espacio" (Heidegger, 2015, p. 6), entonces, no existe hombre y además paisaje, somos paisaje. Ser hombre habla del ser que habita, y al habitar ya se es parte del paisaje.

Construir, en el sentido de abrigar y cuidar, no

1 Avance de revisión teórico-práctica de la Tesis del Doctorado en Urbanismo de PRORB-UFRJ/ Brasil (20172021): El paisaje como experiencia de transformación cultural. Paisaje escuela y campus universitario. Autora: Carla Urbina. Orientadora: Lúcia Maria Sá A. Costa. es ningún producir...El construir (bauen) aquí, a diferencia del cuidar, es un erigir. Los dos modos de construir -construir como cuidar, en latín collere, cultura: y construir como levantar edificios, aedificare- están incluidos en el propio construir, habitar"

(Heidegger, 2015, p. 2)

Ese habitar de Heidegger, en el que estamos incluidos, podría también referirse a las relaciones de afecto con ese espacio construido, habitado, en la "topofilia" de Gastón Bachelard. La topofilia como espacio "vivido, no en su positividad, sino con todas las parcialidades de la imaginación. (...) espacios de posesión, de los espacios defendidos contra fuerzas adversas, de los espacios amados" (Bachelard, 2000, p. 22). Ser te hace cuidar, al preservar o regenerar el paisaje se está cuidando el propio ser.

Es el estado de nuestro paisaje el principal interés, el querer ser una sociedad digna del paisaje que queremos. Burle Marx es el maestro que impulsa este diálogo, afirmando que:

A missão social do paisagista compreende, sem sombra de dúvida, um aspecto pedagógico. Cumpre-Ihe fazer compreender e amar o que a natureza representa, com a ajuda de seus jardins e de seus parques.

Roberto Burle Marx, 1992.

(Leenhardt, 2010, p. 50)

¿Puede entonces el estudio de la naturaleza, la filosofía de educación, experiencias, ser base para el diseño de estrategias, en las que se 
derive una nueva taxonomía de intervenciones responsables en el paisaje? ¿Es posible establecer mejores relaciones con el medio ambiente e intervenir de manera positiva en él, en conocimiento de que es posible con ello transformar los procesos sensoperceptivos, que repercuten directamente en el aprendizaje?

La raicilla de partida hacia la revisión teóricopráctica, que se presenta en este artículo, se resume en dos partes: un Atlas-montaje "Atlas breve de la vida" y un listado de "actitudes" y parámetros que se pretenden explorar en las siguientes etapas de la investigación.

La investigación “El paisaje como experiencia de transformación cultural. Paisaje escuela y campus universitario", tiene la intención de explorar y colectar medios para alcanzar a minimizar la degradación del paisaje, a través de intervenciones que fomenten el desarrollo de experiencias emocionales educativas cotidianas. En este sentido, son estudiados los campus universitarios y entornos educativos, como semilleros para la conformación del paisaje urbano biodiverso, punto de partida para alcanzar los paisajes de la emoción, paisajes escuela. El concepto de paisajeescuela se concibe como parte estructural de sistemas de aprendizaje del ser humano, que es parte integral e indivisible del paisaje.

Esa investigación-acción está basada en el habitar (actividad esencial), construir (dejar habitar), producir (dejar aparecer) de Heidegger, en el aprender por la experiencia de John Dewey, en la idea de "proteger" de Roberto Burle Marx y Marjory Stoneman Douglas, en el accionar de Simmone de Beauvior, en el vivir de Thoureau y todo desde el placer de Epicuro. $Y$ esas líneas de ideas se ven como fragmentos de rizomas a continuación.

\section{ATLAS BREVE DE LA VIDA}

El "Atlas breve de la vida" que se presenta en breve, es un estudio en el que filosofía de la educación, paisaje y ciencias, se entrecruzan y dejan un mapa abierto para continuar explorando. Conocer, aprender sobre la naturaleza es conocernos a nosotros mismos y eso puede ser un paso hacia la concientización y transformación del paisaje cultural.

Basados en el Atlas Mnemosine de Aby Warburg, la idea de rizomas de Delleuze y Guattari, la "Breve historia de tiempo de Hawking y en los estudios de pensar por nebulosas de Berenstein y Da Silva (Berenstein \& Da Silva, 2018); se presenta un primer esbozo del "Atlas breve de la vida", que busca mostrarnos como parte integral e indivisible del paisaje (natural, rural, urbano, arquitectónico), nuestra aparición en él, nuestro lugar dentro del universo de especies, aportes culturales tangibles e intangibles.

Así, se resumen en el siguiente "Atlas breve de la vida": paralelismos en descubrimientos, estudios, transversalidades de ideas, en fin, nuestras vidas son un todo enmarañado de raíces que se entrecruzan y comunican entre sí, como lo hacen los árboles. 
Warburg, nos regala otro nivel de experiencias y el Atlas Mnemosyne como método de enseñanza de arte, habla de cambios constantes, diversos modos de lectura, ruptura de límites temporales. Warburg, como teórico de la imagen, nos proporciona una experiencia laberíntica (Cornell, 2013-2016).

Didi-Huberman (estudioso de la obra de Warburg) afirma que ve las imágenes como "herramientas de conocimiento", un conocimiento como la idea aristotélica experiencial del Pathos (DidiHuberman, 2001).

Más que un archivo, el Atlas Mnemosyne, nos proporciona esos tableros negros que sirven de soporte de montajes (en proceso, como dice la visión de montajes de Walter Benjamín), de imágenes de la historia del arte. Según análisis de Didi-Huberman, el modo de montaje de Aby Warburg, es un experimento de "organización" del caos de ideas, historia y tiempo. Este montaje vincula en una misma plancha imágenes que llegan a interrelacionar tiempos, espacios, personajes y culturas distintas en una misma raíz. Las palabras claves que extremos de los montajes de Warburg serían: heterogeneidad, epistemología, estética (Didi-Huberman, 2001).

El "Atlas breve de la vida, experiencia, ciencia y arte" (Urbina, 2018) interrelaciona ideas de elementos del paisaje sobre tiempoasociaciones-imágenes. Se pretenden entender las relaciones temporales, conceptuales, espaciales, del estudio de los componentes de nuestro universo. Las imágenes que se presentan a continuación son una mera fotografía del estado actual. Sigue posado en una mesa de trabajo, en constante movimiento. Puede verse como un todo inconcluso, o por fragmentos abiertos, y así lo presentamos a continuación.

Fragmento 1: Línea de tiempo. Del origen del universo a nuestros días (base inferior del montaje).

Fragmento 2: Rizomas Phylo-afectivosintelectuales. Árbol de pensadores (derecha).

Fragmento 3: Imágenes de vida. Imágenes de elementos de vida estudiados por el Homo sapiens (centro-izquierda).

En su conjunto se busca descubrir las relaciones de estudios (seleccionados) sobre la vida en la tierra, que el hombre analiza-exploradocumenta-acciona.

\section{FRAGMENTO 1: LÍNEA DE TIEMPO}

Buscamos una comprensión del paisaje que experimentamos y que debemos preservar. Camino para explorar recursos didácticos que nos permitan indagar sobre la vida, experiencias y aprendizaje, en el universo del cual formamos parte integral.

Esta búsqueda permitió elaborar un "Atlas breve de la vida" (haciendo referencia a 


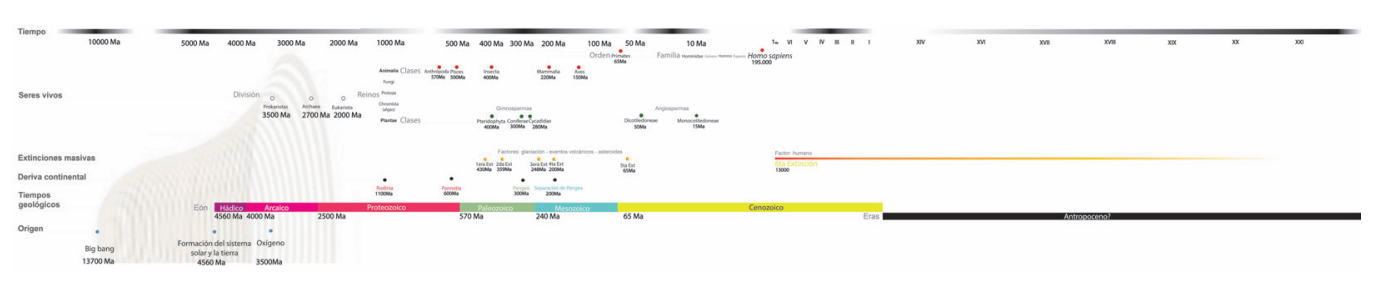

Figura 01.

Tiempo y formación del espacio. Fragmento 1 del Atlas breve de la vida.

la "Breve historia del tiempo" de Stephen Hawking (Hawking S. , 1999)). Ese Atlas nos permite apreciar las asociaciones que tenemos en el tiempo y espacio del paisaje, en un historiograma.

El origen (Big Bang, formación del sistema solar, generación del oxígeno), tiempos geológicos (movimientos continentales, extinciones masivas), seres vivos (Prokariotas, Archaea, Eukariotas -Animalia, Fungi, Protozo, Chromista, Plantae) en un solo gráfico, muestran sus interrelaciones y lógicas (Ver figura 01: Tiempo y formación del espacio. Fragmento 1 del Atlas breve de la vida. Carla Urbina, 2018).

Conocer las causas de las cosas científicamente, refuerzan el rol de cada ser en este universo, incluso nuestro rol como hommo sapiens. Es evidente el poco tiempo que llevamos como especie en el mundo, apenas 195.000años. Es muy poco tiempo geológico que llevamos interviniendo positiva y negativamente.

Roberto Burle Marx, en una de sus conferencias reflexionaba, sobre el tema:
Considerados como colectivos, somos sin duda, los predadores más insensibles e irresponsables que se pude imaginar. Pero el hombre, el individuo, paciente y diariamente, rehace los eslabones frágiles que enlazan nuestra sociedad a la naturaleza. Cría animales. Planta flores. Busca los bosques para relajarse de un trabajo fatigante. Ama el mar, las montañas, los ríos. Esas actitudes evidentemente son minúsculas, toscas y hasta groseras, delante del nivel abrumador de la destrucción. Pero, hay entre ellas, una u otra diferencia, esa radical: mientras la acción individual y consciente, fruto de una comprensión profunda del eslabón hombrenaturaleza, la destrucción es impersonal. Son intereses económicos de grupos, de regiones $y$, a veces, del país entero, que dictan la acción destructora.

(Burle Marx, Arte e Paisagem: Conferências Escolhidas, 1987, pp. 77).

El Atlas puede tener múltiples lecturas, pero, en este momento, la más importante a extraer es que somos un pequeño punto en este universo y una pequeña parte de la historia que tanto tiempo ha llevado. En ese sentido, 
es abrumante ver que el actual proceso de extinción no ha sido el único, pero es la primera vez en el que una especie animal, en este caso el Hommo sapiens, es la causa principal.

La línea de las extinciones masivas muestra la duración de las primeras cinco extinciones, todas por causas naturales-geológicas, choque de asteroides en la tierra, explosiones volcánicas, grandes movimientos sísmicos, glaciaciones. Esta, la sexta extinción masiva, está siendo de gran interés para los científicos, preocupados por la rapidez con la que estamos perdiendo especies. Recientes investigaciones de Paul Elrich, Jan Zalasiewizc, la creciente lista roja de IUCN, nos alertan sobre esta gran mudanza ecológica cuya causa natural, es debido a una de sus especies del reino Animalia: el Homo sapiens. Contaminación, depredación, mudanza de hábitat, cuy a escala de acción y velocidad, han generado tal cambio de hábitats, que difícilmente se dan procesos naturales de adaptación de las especies, llevando a lo que se podría llamar la Sexta extinción masiva (Kaplan, 2015).

\section{FRAGMENTO 2: RIZOMAS PHYLO- AFECTIVOS-INTELECTUALES}

Por otro lado, el descubrimiento de nuestra propia naturaleza despierta deseos de exploración constante a lo desconocido. Tenemos la gran responsabilidad de preservar lo que los átomos se han tardado tanto tiempo en generar. $Y$ a pesar de la gran responsabilidad de intervención negativa en el paisaje, la línea de tiempo continúa hacia la derecha para mostrar los aportes culturales del hombre y su constante deseo de aprendizaje. Porque no toda intervención del ser humano ha sido negativa y puede continuar evolucionando positivamente, conociendo su naturaleza, y lo más importante, reconocer que atentar contra ella es una especie de suicidio.

Esas experiencias genuinas que se dan en sincronía o diacronía se muestran en el lado derecho del Atlas (Ver Figura 02: Asociaciones intelectuales en el Fragmento 2 del Atlas breve de la vida. Carla Urbina, 2018)

Si trazamos líneas imaginarias entre las teorías de la derecha y las imágenes sobre la línea de tiempo, podemos descubrir las raíces de comunicación. La teoría de evolución de Darwin y su árbol evolutivo (1859), fueron inspiración y pauta para Haeckel, y el desarrollo de sus teorías de recapitulación. El camino de Alexander Humboldt en su Viaje por la América equinoccial (1799-1804), fue sendero inspirador para Charles Darwin, para el Viaje en el Beagle (1831-1836).

Cada lector tiene la posibilidad de ir despertando curiosidad y a través de las búsquedas personales, usar el gráfico como hipervínculo, que invita a investigar, volver, descubrir una nueva duda y seguir trazando líneas como en un juego de puntos. 


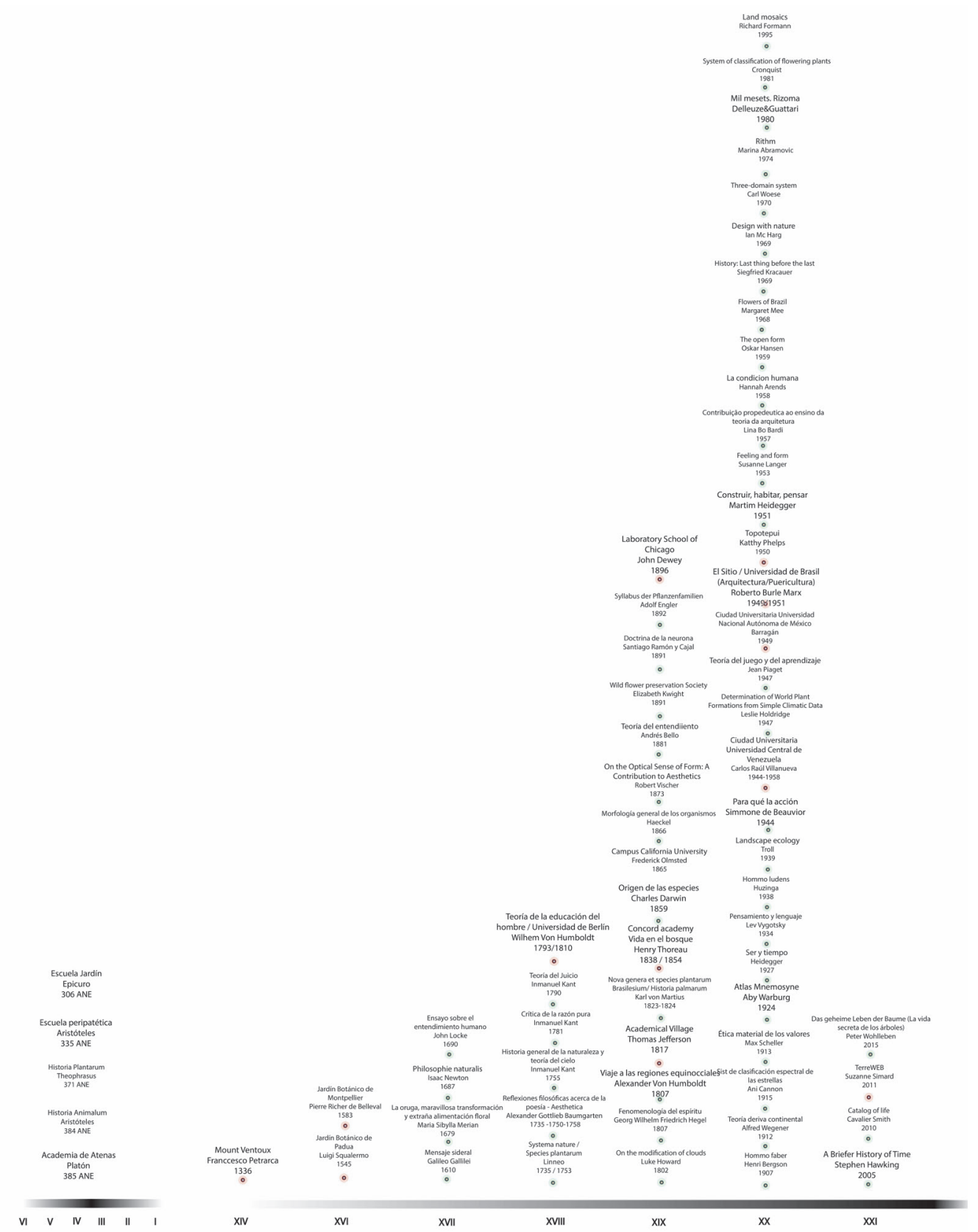

Figura 02.

Asociaciones intelectuales en el Fragmento 2 del Atlas breve de la vida. 
Podemos realizar un mapa (con líneas imaginarias) de proximidades y diferencias conceptuales de teorías de educación, a través de los siglos, enlazando en el gráfico Ios nombres de: Aristóteles (384 ANE), Epícuro (3006 ANE), Arístipo y Areste Cirene (340 ANE), Wilhemm Von Humboldt (1793), Henry Toureau (1838) Thomas Jefferson (1817), John Dewey (1896), Marshall McLuhan (1977) y Susanne Simard (2011). Cada uno de ellos pasa a ser escalón de impulso para las siguientes teorías.

Las asociaciones sanguíneas de Wilhem y Alexander Von Humboldt, desde la filosofía de la educación y deseos de explorar, nos mostraron el mundo. Coincidencias temporales, ideales y espaciales vincularon a Dewey y a Kracauer, en la escuela de la Universidad de Columbia, quienes fueron grandes influencias para las ideas de educación progresiva de Anísio Teixeira (figura importante en la formación de la educación pública brasilera).

Asociaciones empáticas se traducen en paisaje de la mano de Olmstead, Burle Marx, Margaret Mee, lan Mc Harg, su herencia en el paisaje de tantos lugares del mundo que se han convertido en paisaje escuela. Peter Wohlleben con su Wood Wide Web y Suzanne Simard con The science of tree communication, dejan en evidencia las redes de comunicación invisibles, pero efectivas, del intercambio de información que se da tanto desde las raíces como desde el aire o la luz.
Si las partes están preparadas para conocerse y actuar juntas, pueden llegar a crear alianzas genuinas, en un sentido cultural y pleno. Hoy en la era de la información y comunicación, evidencia de ello pueden ser, las apps de sociabilización que reconocen topofilias y empatías; o las asociaciones de preferencias comerciales del sistema Amazon, que reconoce y abre con cada búsqueda una gama de posibilidades de posibles nuevos autores que pueden estar en tu biblioteca. ¿Será posible o necesario convertir este Atlas-montaje en un juego virtual/real con el cual podamos dejar ver nuestras empatías, evidencias e información de nuestra comprensión del paisaje y sus valores?.

Familias genéticas y familias intelectuales (familias de ideas), favorecen el perfeccionamiento simultáneo, asociado, adaptación mutua. Permiten dibujar nuevos mapas, nuevos rizomas Phylo-afectivosintelectuales, que configuran el ecosistema de nuevos paisajes emocionales.

\section{FRAGMENTO 3: EXPLORACIONES DESDE EL ARTE Y LA CIENCIA. SABERES DE LIIMITES DIFUSOS}

Los límites difusos del mundo físico/moral, mente/cuerpo, teoría/práctica, real/virtual, filosofía/ciencia, ciencia/arte, se producen gracias al progreso y transformación de la ciencia moderna. Según Dewey, es el naturalista inglés Darwin, uno de los motores de esa transformación. Sus ideas sobre la evolución, 
selección natural, adaptación, cambio gradual en tiempo y espacio, son gran inspiración, o fragmento del rizoma desde donde inició esta vez.

La influencia de la ciencia, y en particular del método científico, es según Dewey, innegable en todos los aspectos de la vida humana contemporánea: desde las bellas artes hasta los problemas educativos (Dewey, 1964a, pág. 47) cit in (Sandoval Bravo, 2011, p. 13).

Desde el "Origen de las especies" (1859) de Darwin, se transformó el mundo filosófico clásico, a partir de una revolución científica" (Dewey, 2000a, pág. 60) cit in (Sandoval Bravo, 2011, p. 18). El método científico, por medio de la observación, hipótesis y comprobación experimental, puede ofrecer un alcance ilimitado, progresivo, libre, sobre la vida humana.

Las expediciones de Darwin, que abrieron el mundo de la selección natural; los inicios de la neurociencia desde el estudio biológico de las neuronas desde Ramón y Cajal; el empeño de Luke Howard por la comprensión de las nubes y la cambiante narrativa de la atmósfera, construyen desde su ámbito (cada vez más difuso), un espacio abierto, interconectable, adaptable y transformador.

Estas ideas de límites difusos entre ciencia y arte traducidas en imágenes se compilan en el núcleo central del montaje (Ver ilustración
3: Descubrimientos, representaciones desde el arte y ciencia. Fragmento 3 del Atlas breve de la vida. Carla Urbina, 2018). El gráfico completo está vinculado, aunque pueda leerse por fragmentos. La línea del tiempo es la base y sobre ella se posan imágenes desde el arteciencia, representando las investigaciones que han impulsado al hombre a descubrir el universo. De ese modo están ubicadas, relacionando el elemento de interés con la época cultural en la cual fue estudiado. Las imágenes de más abajo son las más antiguas. El tamaño abarca el elemento a estudiar (que se encuentra debajo de la línea de tiempo). Se evidencian las asociaciones de ideas, y como cada una de las ideas es un peldaño para continuar explorando y evolucionando.

Esa construcción, como rizoma, no tiene punto de partida fijo y predeterminado, y por eso se vincula con el arte y ciencia como constructores de procesos educativos. Esta mesa de trabajo que hoy es este montaje (Ver ilustración 4: Atlas breve de la vida. Carla Urbina, 2018), puede convertirse en un juego de rompecabezas, que nos permita continuar sumando en esa línea de tiempo tantas ideas y experiencias sean necesarias para continuar interviniendo en nuestro paisaje-escuela.

\section{APRENDER DE LA EXPERIENCIA, ENSEÑAR CON LA ACCIÓN, CREAR ASOCIACIONES EMPÁTICAS}

A partir de ese escalón que nos da el Atlas- 

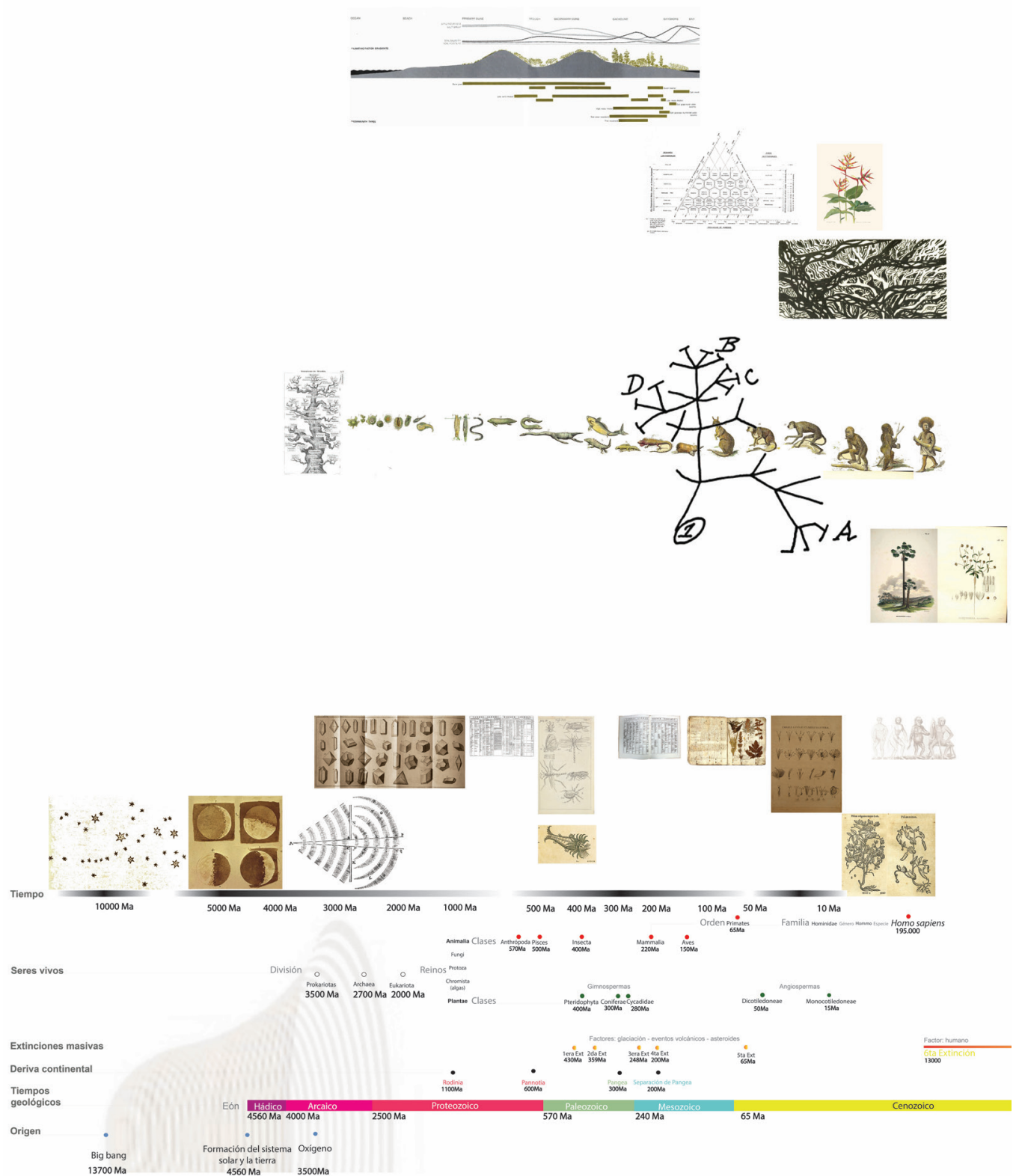

Figura 03.

Montaje. Rizoma de la vida. Basado en el árbol de la vida de Charles Darwin y la teoría rizomática de Delleuze \& Guattari. Urbina, 2018. 


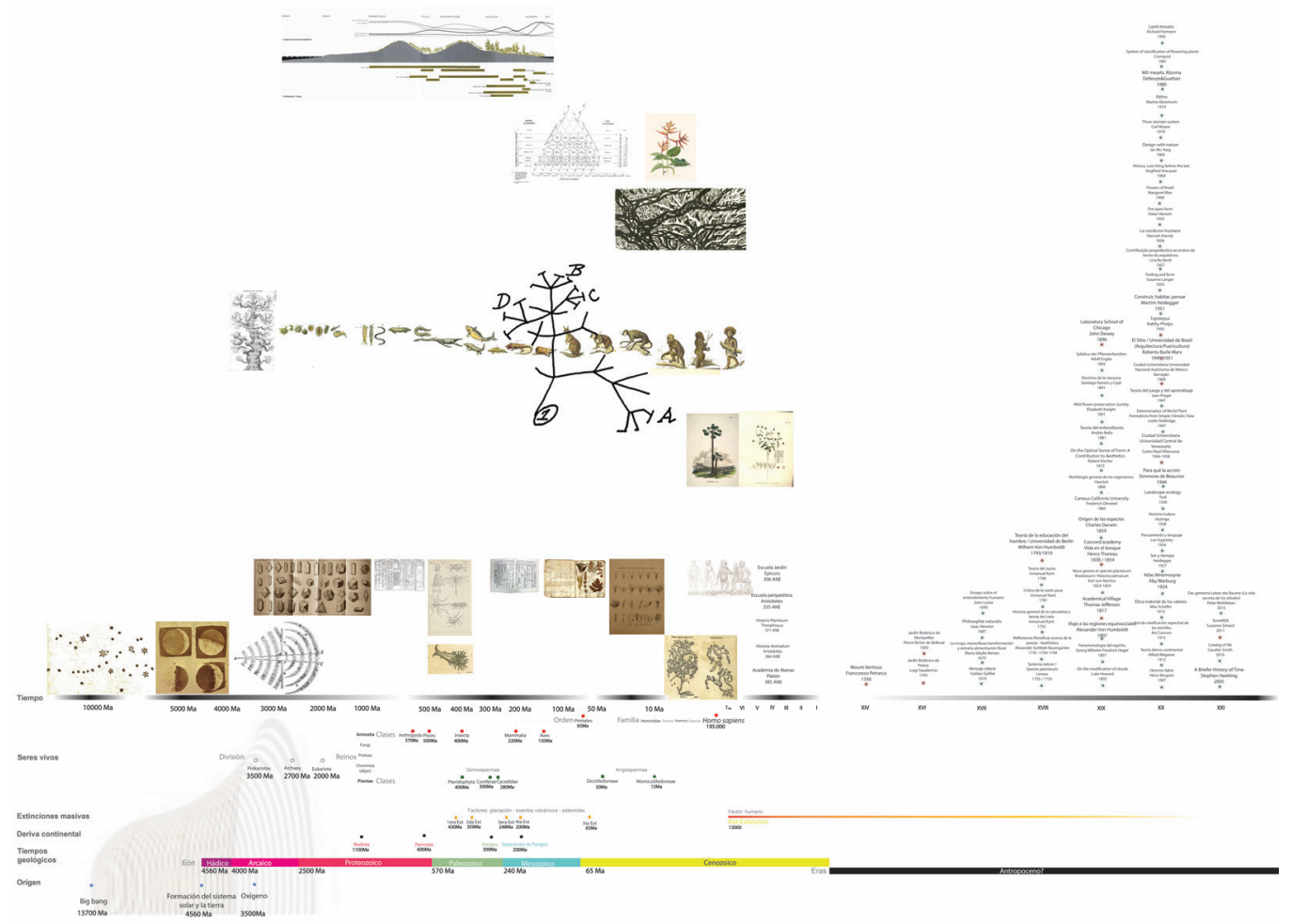

Figura 04.

Descubrimientos, representaciones desde el arte y ciencia. Fragmento 3 del Atlas breve de la vida. 
montaje, seleccionamos "autores guía" sobre paisaje, educación y experiencia, desde la ciencia y el arte. La idea es marcar posibles actitudes ante el mundo y experiencias de la investigación, que, al fin y al cabo, son actitudes de vida, ya que “Vida experiencia y aprendizaje no pueden separarse. Simultáneamente vivimos experimentamos y aprendemos" (Dewey J., 1952, p. 10).

Se estudian las experiencias de diversos autores guías (Epicuro, Simonne de Beauviour, Petrarca, Thoureau, Alexander Von Humboldt, Charles Darwin, Delleuze \& Guattari, Franz Kafka, Walter Benjamin, Mary Stoneman Douglas, Valentina Quintero, Roberto Burle Marx); y se toman los aprendizajes personales, historias, mapas, artículos, post, relatorios, conferencias y procesos, como punto de partida para el marco teórico-práctico de la investigación-acción que se encuentra en proceso.

- Aprender desde el placer.

- Vivir nuevas experiencias.

- Narrar lo vivido o sobrevivido.

- Accionar y resistir con terquedad.

- Territorializar valores.

La búsqueda no es crear un método, es montar mapas posibles, armar mesas de trabajo, descubrir secuencias, actitudes, conocer aciertos y errores, orígenes, historia, valores.

\section{APRENDER DESDE EL PLACER}

Con Epícuro como autor guía, retomamos su jardín escuela, para reforzar la idea de la casa como primera escuela, hasta el paisaje como gran aula de aprendizaje continuo, donde el aprendizaje se dé por la felicidad y conquista del placer. Además de resaltar una de las máximas de Epicuro sobre la importancia de la investigación de la naturaleza como vía para evitar temores y para la obtención de placeres puros (García Gual, 2002, p. 62).

Reafirmando ese planteamiento, citamos a Simone de Beauvoir: "El goce no es una separación con el mundo, supone mi existencia en el mundo" (Beauvoir, 2000, p. 18). "No hay goce sino cuando salgo de mis mismo y es, a través del objeto, que comprometo mi ser en el mundo" (Beauvior, 2000, p. 19).

\section{VIVIR NUEVAS EXPERIENCIAS}

Petrarca desde su relato de "La ascensión al Mont Ventoux" y Thoureau con "La vida en el bosque", nos invitan a vivir tantas experiencias como sea posible, siempre desde el deseo personal.

Es necesario viajar, vivir nuevas experiencias, porque "Ningún método ni disciplina puede reemplazar la necesidad de estar siempre alerta” (THOREAU, 2011, p. 23) y “...mientras estemos confinados a los libros, aun los más selectos y clásicos, y leamos solamente las 
lenguas escritas locales (que no son por su parte sino dialectos provinciales), correremos peligro de olvidar el lenguaje que hablan sin metáfora todas las cosas y sucesos..." (THOREAU, 2011, pp. 23,24).

Extraemos de las experiencias de Petrarca y Thoureau: la exploración con la motivación del placer, buena selección de compañeros de viaje, valoración del tiempo de descanso, reflexión, disfrute de la belleza y el trabajo realizado, visualización como parte del proceso, lecturas previas como inspiración, lecturas en viaje como reflexión y reforzamiento de aprendizaje, compartir las experiencias de vida, deseo de registro de lo vivido.

\section{NARRAR LO VIVIDO}

Viajes de campo, montajes de mapas de antecesores, plan claro, alianzas, estar con los mejores equipos (personal y material), aprovechar recursos, documentación rigurosa (antes, después, recopilación de objetos perdidos), análisis-propositivo, comprender la importancia e influencia del hogar como escuela, dejar registro de mejora de material previo para mejorar; son parte del aprendizaje que retomamos de las experiencias de Humboldt (Viaje por la América equinoccial 1799-1804), Charles Darwin (Viaje en el Beagle1831-1836).

¿Cuál será nuestro Beagle? ¿Quiénes serán nuestros amigos/colegas; Bonpland (ilustrador), Fitz Roy (mapas), Darwin (colectas),
Conrad Marteens (paisajista), ¿Joseph Hooker (botánico)? ¿Cómo registrar la bitácora: Cartas, email, whatasaap? ¿Instagram, web, app?

\section{ACCIONAR Y RESISTIR CON TERQUEDAD}

Simonne de Beauvoir (del libro Para qué la acción), Mary Stoneman Douglas (y su trabajo constante en la Protección de los Everglades de Florida, EEUU) y Valentina Quintero (con sus viajes y difusión de valores de los paisajes de Venezuela), nos enseñan con sus acciones, sobre: terquedad como método, el poder de la palabra rigurosa, denuncia a través de la pasión, denuncia como inicio de rescate o construcción, acción en la gestión, trabajo constante, exploración, registro, difusión y muestra de valores.

Territorializar valores

Una de las preocupaciones de Burle Marx era que “...El hombre del interior conocía las plantas de su región. Sabía de la utilidad específica de muchas maderas y conocía los usos y peligros de muchas hierbas. Distinguía las floraciones y tenía conocimiento de la fauna regional (...) Pero, a medida que el hombre se desvincula de su tierra, cuando el nordestino es transferido para Amazonia, cuando ondas y ondas de migrantes van para otras regiones, huyendo de la miseria, no podemos esperar de ellas esa conciencia' (Burle Marx, Arte e Paisagem: Conferências Escolhidas, 1987, pp. 77-). Es la desterritorización, parte del problema de la degradación de paisaje. 
Territorializar, es la acción para aprender valores del paisaje personal, conocer las especies de la región: vivir, usar, enseñar, aprender, cuidar. Es la acción de concientizar a los pueblos ricos en materia prima para valorar su tierra, aprender a usarla, comprender los valores de sus condiciones naturales y exaltarlos. Pasar de la destrucción, extractivismo desmedido (que se revierte en una posible migración masiva por falta de recursos); al uso responsable y equilibrado del paisaje y traspaso de conocimiento por generaciones.

Territorializar minimiza las interferencias ilógicas sobre el paisaje, es un modo de vivir el paisaje de modo que el alma del lugar prevalezca sobre cualquier capricho o decisión impuesta, invasiva o destructiva.

Aprender de la experiencia, enseñar con la acción es dejar visible las fuerzas activas en algunas experiencias, para que los compañeros de viaje y próximos exploradores decidan cuales toman o dejan, si sirve o no, para dejar la posibilidad de crear nuevas verdades contingentes que creen nuevas experiencias. La acción no es un hecho aislado, el ideal es que sea parte de un sistema particular, generador empatías, asociaciones y alianzas que amplían la red de accionar responsable en el paisajeescuela.

\section{BIBLIOGRAFÍA}

BACHELARD, G. (1957). La poética del espacio. Buenos Aires: FCE.

BARING, T. C. (1884). The scheme of Epicurus. Londres: Kegan Paul Trench \& Co.

BBC. (sf). BBC Earth Timeline. Recuperado desde http://www.bbc. co.uk/science/earth/earth_timeline

BEAUVIOR, S. de (2000). Para qué la acción. Recuperado desde http://biblioteca.salamandra.edu.co/libros/Beauvoir,\%20Simon\%20 de\%20-\%20Para\%20que\%20la\%20accion. pdf

BENJAMIN, W. (2005). Libro de los pasajes. Madrid: Akal.

BERENSTEIN, P., \& DA SILVA, M. (2018). Nebulosas do pensamento urbanístico. Salvador de Bahia: EDUFBA.

BURLE MARX, R. (1987). Jardim e ecologia. En TABACOW, J. Roberto Burle Marx arte e paisagem São Paulo: Studio Nobel. p. 85-95.

BURLE MARX, R., \& TABACOW, J. (2004). Arte e paisagem: conferências escolhidas. São Paulo: Studio Nobel.

BURLE MARX, R. (2010). Paisagem, botânica e ecologia. Perguntas a Roberto Burle Marx. En LEENHARDT, J. Nos jardins de Burle Marx. São Paulo: Perspectiva.

CORNELL. (2013-2016). Warburglibrary. Recuperado desde https://live-warburglibrarycornelledu. pantheonsite.io/ 
DARWIN, C. (1859). The origin of species. 150th Anniversary Edition. Florida: Bridge Logos.

DARWIN, C. (1860). Journal of researches during the voyage of HMS Beagle. London: Collins.

DELLEUZE, G. \&. GUATTARI, F. (1994). Rizoma. México: Coyoacán.

DEWEY, J. (1938). Experience \& education. New York: Kapa delta pi.

DEWEY, J. (1952). Vida e educação (3a.ed.) São Paulo: Melhoramentos.

DEWEY, J. (1959). Democracia e educação. São Paulo: Companhia Editora Nacional.

DEWEY, J. (2008). El arte como experiencia. Barcelona: Paidós.

DIDI-HUBERMAN, G., \& BERGMANN, L. (ed.) (2001). Atlas. How to carry the world on one's back? Freiburg im Breisgau, Deutschland: Warburg Library Cornell. Recuperado https:// vimeo.com/24023841

FLORIDO, J. (1999). Os pré-socráticos. São PauIo: Nova Cultural.

FORMAN, R. (2004). Mosaico territorial para la región metropolitana de Barcelona. Barcelona: Gustavo Gili.

GARCÍA GUAL, C. (2002). Epicuro. Madrid: Alianza.

HAWKING, S. (1999). Uma breve histórica do tempo (A brief history of time: from the Big bang to black holes, 1988). Rio de Janeiro:
Rocco.

HAWKING, S. (2001). O universo numa casca de noz (The universe in a nutshell). São Paulo: Mandarim.

HAWKING, S. (s.f.). The beginning of time. Recuperado desde http://www.hawking.org.uk/ the-beginning-of-time.html

HEIDEGGER, M. (2015). Construir, habitar, pensar. Madrid: La Oficina.

KAPLAN, S. (22 de junio de 2015). Earth is on brink of a sixth mass extinction, scientists say, and it's humans' fault. Washington Post. Recuperado desde https://www.washingtonpost. com/news/morning-mix/wp/2015/06/22/ the-earth-is-on-the-brink-of-a-sixth-mass-extinction-scientists-say-and-its-humans-fault/? noredirect=on\&utm_term $=.3 c 997$ ccd5491

LEENHARDT, J. (2010). Nos jardins de Burle Marx. São Paulo: Perspectiva.

LUCRÉCIO. Epicurismo e "Da Natureza”. Brasil: Ediouro.

NEWTON, I. (1974). Princípios matemáticos (PhiIosophie Naturalis Principia Mathematica, 1687). São Paulo: Abril.

PETRARCA, F. (2002). La ascensión al Mont Ventoux. Madrid: Artium.

QUINTERO, V. (s.f.). La guía Valentina Quintero. Recuperado desde http://www.va_lentinaquintero.com.ve 
REED, C., \& LISTER, N.M. (2014). Ecology and design: parallel genealogies. Places Journal, apr. 2014. Recuperado desde https://placesjournal.org/article/ecology-and-design-parallel-genealogies/\#ref_14

SANDOVAL BRAVO, J. (2011). La reconstrucción de la experiencia. Bogotá: Pontificia Universidad Javeriana.

STONEMAN DOUGLAS, M. (1990). The voice of the river. Sarasota: Pineapple Press.

TEIXEIRA, A. (1951). Um presságio de progresso. São Paulo: Habitat.

THOUREAU, H. D. (2011). Walden. La vida en los bosques (1817-1862). Buenos Aires: Juventud.

\section{FUENTE DE IMÁGENES}

Elaboración propia a partir de fotografías y gráficos realizados para la propuesta de tesis: "El paisaje como experiencia de transformación cultural. Paisaje escuela y campus universitario". 